\title{
On Translation of Electric Power English from the Perspective of Translation Aesthetics
}

\author{
Min Shen \\ School of Foreign Languages, North China Electric Power University, Beijing, China \\ Liangqiu Lv \\ School of Foreign Languages, North China Electric Power University, Beijing, China
}

\begin{abstract}
The translation of electric power English is getting prominent with the expanding of national grid and frequent exchanges of power industry among countries. From the perspective of translation aesthetics, electric power English translation is a language transformation activity that combines science and art together. Beginning with introduction to translation aesthetics theory and electric power English, under three criteria for judging aesthetic value of electric power English, this paper shall probe into the beauty of accuracy, conciseness, rhetoric and logic of electric power English and its translation. On the basis of analysis, translation techniques are proposed to represent these beauties in light of translation aesthetics.
\end{abstract}

Index Terms - electric power English, translation aesthetics, EST, translation techniques

\section{INTRODUCTION}

Translation of EST (English for Science and Technology) plays an increasingly important role in frequent and deep scientific and technological communications across the world. For some time, translation aesthetics has only been applied to the study of literature translation while ignored in EST translation. Although language of EST is not as charming as that of literature, non-literary language has its unique aesthetic value. Electric power English involves a wide range of professional knowledge, frequent use of terminologies and complex expression structures. Electric power English, a branch of EST, is also featured in aesthetic value. The translation of electric power English shall reproduce the original aesthetic features via meeting aesthetic criteria.

\section{THEORY OF TRANSLATION AESTHETICS}

In Practical Translation Aesthetics, Zhongxuan Fu (1993) holds that "translation is an aesthetic avtivity in which aesthetic subject of translation (translator) transfers aesthetic object of translation SL (source language) text into another aesthetic object of translation TL (target language) text by aesthetic medium (translators' aesthetic consciousness)" (p. 2). Ronggui Mao (2005) assumes that in translation, translation objects refer to SL and TL while translation objects are translators, editors and readers among which translators play the leading role (p. 22). In Miqing Liu's An Introduction to Translation and Aesthetics (2012), non-literary translation is discussed from aesthetic perspective, which constitutes a breakthrough of aesthetic translation study.

The theory of translation aesthetics believes that translation seeks aesthetic equivalence and dynamic integration between SL text and TL text in consideration of aesthetic value and aesthetic criteria. In the practice of translating electric power English, translators, on the basis of their aesthetic consciousness, are supposed to understand and appreciate beauty of electric power English text and represent the original beauty in Chinese version.

\section{BRIEF INTRODUCTION To ELECTRIC POWER ENGLISH}

Electric power English is a kind of specialized English. In general, electric power text involves a wide range of professional knowledge, frequent use of terminologies and complex expression structures.

Mengzhi Fang and Zhongming Mao (2005) categorize technology text into "specialized technology text" and "non-specialized technology text". Similarly, electric power text can be classified into "specialized electric power text" and "non-specialized electric power text". These two kinds of texts are different in content and language features. "Specialized electric power text" encompasses electric monograph, patent documents, technical standards, technical contracts, scientific papers of electric power application and so on. "Specialized technology text" is objective and logical with formal written style and prudent use of words. "Non-specialized electric power text" embraces operating procedures and regulations, maintenance manual, safety rules, product specification, materials for promoting electric power products, popular science books about electric power and so on. "Non-specialized technology text" is featured in plain words and clear sentence structures with frequent use of rhetoric (p. 91). Both specialized and non-specialized electric power text share common aesthetic features. 


\section{Aesthetic Criteria of Electric Power English Translation}

Both specialized and non-specialized electric power text share common aesthetic features. Similar to literary translation, electric power English translation enjoys beauty in content and form, but limited by its scientific style, its content should be accurate and true. Three aesthetic criteria, accuracy, conciseness and scientificness, should be fulfilled.

\section{A. Accuracy}

Shuchun $\mathrm{Xu}$ (1984) emphasizes that accuracy is the soul of EST translation (p. 26-28). Accuracy is the primary standard in electric power English translation, thus, ambiguity and mistakes should be avoided especially in the cases of polysemy.

\section{B. Conciseness}

Xiaowa He (1995) insists that "beauty of science lies in conciseness" (p. 12-13), which means a compact structure and concise use of vocabularies. In electric power text, nominalization and terminologies are used instead of sentences and abbreviations are used in place of whole words to follow the criterion of conciseness.

\section{Scientificness}

Electric power text should be scientific as it belongs to category of scientific text. Its scientificness lies in precise use of terminologies, prudent choice of words, and rational arrangement of syntax.

\section{BeAuty of Electric Power ENGLish}

The aesthetic features of electric power English are expressed as beauty of accuracy, conciseness, rhetoric and logic. This part shall focus on analysis of these beauties in electric power English text and its translation.

\section{A. Beauty of Accuracy}

The beauty of accuracy is mainly reflected in precise understanding of the original text and choices of word meanings as polysemous terminologies are frequently used.

Example 1: This excess of generation if then available for picking up suddenly applied customer loads or to pick up the load dropped by a generator that must be removed from service for emergency maintenance.

Translation: 超额的发电量, 可用于担负突然接入的用户负荷, 或因紧急维修而必须退出运行的发电机所甩掉 的负荷。

Example 2: Pick up the 5EX relay by pushing the relay button and force L20FGX and L4X1 to logic “1”.

Translation: 按下继电器按钮而将继电器 5EX 吸合, 使 L20FGX 和 L4X1 处于逻辑状态“1”。 (From Theory and Practice of Electric Power Translation Between English and Chinese, p. 114)

Example 3: Check the magnetic pickup if it is installed correctly.

Translation: 检查磁性传感器是否安装妥当。(From Theory and Practice of Electric Power Translation Between English and Chines, p. 114)

In the above three examples, the same phrase “pick up” is translated into “担负” “吸合” and “传感器” (pickup) in different contexts for accuracy. Understanding of neighboring words such as "load" "relay" and "magnetic" and knowledge of electric power contribute to comprehension of phrase "pick up."

\section{B. Beauty of Conciseness}

Electric power text delivers the most information with the least use of words. Simplicity of the text is mainly embodied in the extensive use of nominalization structure.

Example 4: Electronics is the study of the flow of electrons and the application of such knowledge to practical problems in communication and controls.

Translation: 电子学研究电子运动规律, 并把这种知识运用于通信和控制的实际问题。(From Theory and Practice of Electric Power Translation Between English and Chinese, p. 143)

In example 4, two noun phrases “the study of" and “the application of" are translated into two verbs “研究” and “运 用” respectively in Chinese, which makes the translated version concise and fluent.

\section{Beauty of Rhetoric}

The function of rhetoric is categorized into aesthetic rhetoric and communicative rhetoric. Yushan Zhao and Liangqiu Lv (2013) hold that communicative rhetoric is mainly used in electric power text and subjective language should be avoided in electric power text (p. 47). Shoukang Yang (2004) insists that aesthetic rhetoric highlights vividness, activeness and elegance of language to achieve artistic functions. Although it is required that the electric power text should be objective, accurate and scientific without personal feelings, appropriate rhetoric can remove stereotypes of "stiffness" and "coldness" of power technology text. Rhetoric of personification, simile and metaphor is most commonly used in electric power English.

\section{a. Personification}


Personification is a figure of speech to compare one thing (including objects, animals, thoughts or abstract concepts) to a person by endowing it with human being's appearances, personalities or emotions. Embodied via adjectives, verbs or nouns, personification can evoke aesthetic imagination and empathy.

Example 5: Automatic machines having many advantages can only do the jobs they have been "told" to do.

Translation: 自动化机器虽然有许多优点，但只能做人们“吩咐”的事。

In example 5, instead of “告知”, “had been told to" is translated into a more touching Chinese expression “吩咐” which manifests the superordinate-subordinate relationship between human and automatic machines, through which it pictures an obedient, helpful and friendly image of automatic machine.

b. Simile

A simile is a figure of speech that makes a comparison, showing similarities between two different things through words "like", "as" "resemble" or "seem" and so on. Normally, simile includes three parts: subject, reference and indicator of resemblance. In translating, the vivid comparison should be represented and artistic image should be integrated to deepen readers' aesthetic sense.

Example 6: The porous wall acts as a kind of seine for separating molecules.

Translation: 多孔壁就像一把管子，能把质量不同的分子分开。

In example 6, porous wall whose function is separating molecules is compared to a kind of seine, which evokes readers' imagination for an abstract porous wall on the basis of a concrete image of seine.

\section{c. Metaphor}

Metaphor is a figure of speech which makes an implicit, implied or hidden comparison between two things that are unrelated but share some common characteristics. The purpose of metaphor is basically twofold: "the first purpose is cognitive, the second aesthetic" (Peter Newmark, 1988, p. 103). In translating, the image of metaphor is better to be kept for aesthetic sake, but it may be replaced for exact understanding of professional concepts of power technology related areas.

Example 7: Electric power has been the servant of man ever since the invention of motor.

Translation: 电动机发明以来, 电力一直为人类服务。

In example 7, the metaphor shows the relationship between man and electric power and electric power is regarded as servant of human beings. Normally "servant" refers to someone who performs duties or serves a master. The noun “servant” is translated to a verb structure “为人类服务”instead of “人类的仆人” to make it sound more objective.

\section{Beauty of Logic}

Shoukang Yang (2004) holds that the most unique beauty of EST lies in its logical beauty since EST texts involve scientific concepts, principles and facts (p. 15-18). In translating, sentence structure should be analyzed among which hidden logic should be sorted out and organized in order.

Example 8: Motor action results when the effects of the currents in the two windings are such that a unidirectional torque is produced on the rotor and is of sufficient magnitude to overcome the opposition to rotation caused by the load on the motor shaft.

Translation: 电流流经这两个绕组, 在转子上就会产生单向转矩, 并且当该转矩大于由电机主轴载荷引起的反 向转矩时, 电机就会启动。

This sentence explains how motor starts to work. The stem of this sentence is an adverbial clause of condition led by "when". In translating, this sentence is divided into meaning groups: motor action results / when the effects of the currents in the two windings / are such that / a unidirectional torque is produced on the rotor / and is of sufficient magnitude / to overcome the opposition to rotation caused by the load on the motor shaft/. In the Chinese version, the conditions are placed ahead of the motor actions, ensuring the clarity of understanding the sentence.

\section{TRANSLATION TECHNIQUES FOR AESTHETICS REPRESENTATION}

Aesthetic representation is a crucial process that carries out aesthetic activities (Miqing Liu, 2012, p.183). In this part, translation techniques including diction, omission, use of four-character structure, reserve and removal of rhetoric, inversion and division are suggested for the translation of electric power English for representing beauty of accuracy, conciseness, rhetoric and logic.

\section{A. For Beauty of Accuracy}

Translators should confirm the meaning of terminology through comprehension of context, neighboring words in particular and professional knowledge for beauty of accuracy.

\section{Diction}

In electric power English, exact Chinese equivalents should be found to ensure accuracy of the text as the same technical jargon has various meanings in different context. It requires specific knowledge and critical judgment in diction.

Example 9: Before the air enters the turbine, fuel is sprayed into it.

Translation: 在空气进入涡轮之前, 燃料就喷进了。 
Revised translation: 在空气进入燃气轮机之前, 先喷入燃料。

Example 10: After rotating the turbine by the turning gear, allowing time for the rotor to assume a straight plane (no bowing), and the turning gear is disengaged and steam is admitted to the turbine to slowly warm the turbine.

Translation: 通过盘车转动涡轮机, 留出一定的时间让转子保持水平 (无弯曲), 然后解开盘车, 让蒸汽进入 涡轮机慢慢暖机。

Revised translation: 通过盘车转动汽轮机, 留出一定的时间让转子保持水平 (无弯曲), 然后解开盘车, 让蒸 汽进入汽轮机慢慢暖机。

A turbine is a rotary mechanical device that extracts energy from a fluid flow and converts it into useful work. Turbine can be categorized into gas, steam and water turbine. In translation, jargons should be exact and accurate. Getting a grip on neighboring words helps translators to find the exact jargon. In example one, the word "fuel" indicates that the "turbine" is gas turbine and in example two, the word "steam" indicates that the "turbine" in discussion is steam turbine. For the beauty of accuracy, the same word "turbine” is translated into “燃气轮机” and “汽轮机” respectively.

\section{B. For Beauty of Conciseness}

Techniques of omission and conversion can be used to achieve beauty of conciseness in electric power English. Besides, if compendious Chinese four-character structures are properly used, beauty of conciseness shall be greatly sensed.

\section{a. Omission}

English is a hypotaxis-prominent language while Chinese a parataxis-prominent one. With the premise that complete information is delivered, some English components such as pronouns, conjunctions, prepositions, determiners and sometimes even verbs can be omitted in E-C translation to maintain conciseness.

Example 11: There are two different kinds of electricity, which we call positive electricity and negative electricity.

Translation: 有两种电, 我们把它们称作正电和负电。

Revised translation: 电有两种: 正电和负电。(From Methods and Techniques of E-C Translation for Electric Power Technology, p.36)

In the first translation version, the English structure is duplicated, however, in the revised translation, without meaning ellipsis, "which we call" is omitted and replaced by a colon. The number of Chinese characters in revised translation is almost half as many as that of the first translation version.

\section{b. Conversion}

Conversion is to change part of speech into another. In electric power English, nominalization-structure can be conversed to verb-structure to conform to Chinese aesthetics.

Example 12: Fuse has found application for the protection of power system.

Translation: 熔断器的作用是用于保护电力系统。

Revised translation: 熔断器用于保护电力系统。

The nouns “application” and “protection” are conversed to Chinese verbs “用于” and “保护” which are concise and more native. In the revised translation, “作用是” is omitted since it repeats meaning of “用于”.

\section{c. Use of Four-character Structure}

Four-character structure embodies aesthetics through its rich contents, lively rhythms and tidy forms. On the basis of comprehension, proper use of four-character structure embodies conciseness of Chinese. Besides, as Chinese is a tone language, appropriate four-character structures make Chinese translated version more musical.

Example 13: These pumps are featured by their simple operation, easy maintenance, low consumption and durable service.

Translation: 这些水百具有易于操作、易于维修、消耗量低和耐用的特点。

Revised translation: 这些水原操作简便、维修容易、耗油量少、经久耐用。(From Theory and Practice of Electric Power Translation Between English and Chines, p. 62)

In example 13, parallelism is embodied in the four "adjective-noun" structures, which injects musical rhyme into the description of features of these pumps. In Chinese revised version, four "verb-adverbial" structures represent the rhyme of the original four paralleled and forceful phrases and make the Chinese version concise and fluent.

\section{For Beauty of Rhetoric}

Electric power English text is objective and logical with formal written style, but proper rhetoric devices can make the cold and stiff scientific content easy to understand, more aesthetic and less obscure. Through literal translation, the image of rhetoric shall be remained and knowledge related to electric industries shall be illustrated in a vivid way, however, if keeping the image of rhetoric may twist the meaning of the original text, translators may sacrifice rhetoric image to follow the accuracy rule as the first choice through liberal translation.

\section{a. Reserve of Rhetoric}

Rhetoric should be remained if the information is precisely delivered with vivid rhetoric through literal translation.

Example 14: Electricity flows through a wire just as water flows through a pipe.

Translation: 电流通过导线, 就像水流通过管道一样。 
In example 14, the dynamic movement of "electricity flows through a wire" is compared to "water flows through a pipe". For readers who lack imagination for a scene of flowing electricity in a wire, this photographic simile can link scenes that readers already know to phenomenon of electric power.

\section{b. Removal of Rhetoric}

Rhetoric should be removed if ambiguity and confusion are aroused in translated version through liberal translation.

Example 15: Whichever way the two two-way switches are left, one of the wires is "alive" and the other is "dead".

Translation: 无论这两个双路开关合在哪一边，两根导线中总有一根是“活的”，一根是“死的”。

Revised translation: 无论这两个双路开关合在哪一边, 两根导线中总有一根是带电的, 一根是不带电的。

In this example, "wires" are endowed with life as they can be "alive" or "dead" just like mortals. But in electric power English, "alive" and "dead" expounds specific electric phenomena: the "livewire" or "live wire" refers to a wire with a flow of electrical current while the "dead wire" means no flow of electrical current in a wire. If "alive" and “dead” are translated into “活的” “死的” respectively, readers may feel confused as they assume that the wire that is alive can be used but the dead wire fails to function. In this case, removal of rhetoric is preferred for readers' understanding.

\section{For Beauty of Logic}

Accurate representation of original meaning is based on analysis of sentence structure and comprehension of professional knowledge and logical expression in Chinese. In translating, hidden logic should be sorted out and organized in order for the sake of readers' better understanding.

\section{a. Inversion}

Information order illustrates people's thinking patterns. Inversion is a translation technique which means necessary change of word-order in accordance with the expression habit of target language.

Example 16: It is much easier to make the determination of the motion from dynamical principle if this part of the question is separated from the other, which belongs properly to Mechanics, than if the two parts were undertaken conjointly.

Translation: 从动力学原理研究运动会更容易, 如果把第一部分和本来属于机械学的那一部分分开, 而不是综 合考虑两部分。

Revised translation: 把第一部分和本来属于机械学的那一部分分开, 从动力学原理研究运动, 这比把两部分合 起来考虑容易得多。

In Chinese, comments are normally placed after facts while in English the exact opposite. In the revised translation, the comment of "it is much easier" is placed at the end of the sentence to conform to Chinese expression habit.

\section{b. Division}

Division is a translation technique which refers to necessary splitting of a long sentence into several shorter parts. Through division, knowledge related to electric power English can be reorganized in a logical way.

Example 17: The leakage current from each circuit conductor to the grounding conductor is to be calculated by dividing the voltage indicated by the voltmeter by the accurately known resistance of the resistor.

Translation: 从每条电路导线到地线的漏电, 应该用由电压表显示的电压除以电阻器上的已知电阻计算出来。 Revised translation: 电表所示的电压, 除以电阻器所示的已知电阻, 可计算出每根导线到地线的漏电情况。

The original text is a long sentence that describes the calculation of leakage current. The first translation duplicates the original structure through liberal translation strategy, which is still difficult to understand. In translating, the long sentence is divided into the following sense groups: The leakage current from each circuit conductor to the grounding conductor / is to be calculated / by dividing the voltage indicated by the voltmeter / by the accurately known resistance of the resistor /. After division, the calculation of leakage current is quite clear. Then it requires the translator to reorganize the sentence in accordance with Chinese expression ways by placing the calculation method ahead of the calculation result.

\section{CONCLUSION}

For quite a long time, translation aesthetics is exclusively used in studying literature translation while EST translation is required to be objective, unaffectionate and cold. Translation of electric power text is also supposed to be stiff and unemotional. But from the perspective of translation aesthetics, electric power English translation is an activity of aesthetic transformation that blends the beauty of science and art together. This requires that translators should cultivate their aesthetic consciousness in pre-translating; excavate aesthetic elements and unleash their aesthetic appreciation during translating; represent aesthetics of original text and achieve aesthetic transformation in language, style, thinking pattern and aesthetics in post-translating.

\section{ACKNOWLEDGEMENTS}

This research was financially supported by the Education Reform Program issued by North China Electric Power University and the Fundamental Research Funds for the Central Universities. 


\section{REFERENCES}

[1] Fang, M.Z. \& Mao, Z. M. (2005). A coursebook on pragmatic translation. Shanghai: Shanghai Foreign Language Education Press, 91-108.

[2] Fu, Z.X. (1993). Practical translation aesthetics. Shanghai: Shanghai Foreign Language Education Press, 2.

[3] He, X.W. (1995). Aesthetic consciousness and aesthetic cultivation of EST translation, Shanghai Journal of Translators 4, $12-13$.

[4] Liu, M.Q. (2012). An introduction to translation and aesthetics ( $2^{\text {nd }}$ ed.). Beijing: China Translation \& Publishing Corporation.

[5] Mao, R.G. (2005). Translation aesthetics. Shanghai: Shanghai Jiao Tong University Press, 22.

[6] Newmark, P. (1988). A textbook of translation. Hemel Hempstead: Prentice Hall International LTD, 103.

[7] Xu, S.C. (1984). Accuracy-the soul of EST translation. Chinese Translators Journal 2, 26-28.

[8] Yang, S.K. (2004). On aesthetics and aesthetic reflection of EST. Shanghai Journal of Translators for Science and Technology 3, 15-18. doi: 10.3969/j.issn.1672-9358.2004.03.004.

[9] Zhao, Y.S. \& Lv, L.Q. (2013). Theory and practice of electric power translation between English and Chinese (eds.). Hebei: Hebei University Press.

[10] Zheng, Y.C. (2002). Methods and techniques of E-C translation for electric power technology. Beijing: China Water \& Power Press.

Min Shen was born in Ningxia, China in 1991. She is a Master Degree candidate from School of Foreign Languages in North China Electric Power University. She received her Bachelor Degree in English major from Xi'an International Studies University in 2015.

Liangqiu Lv was born in Anhui, China. He is a professor in the School of Foreign Languages, North China Electric Power University. His research interests cover English teaching, Translatology and science and technology translation. He is a co-editor of Theory and Practice of Electric Power Translation between English and Chinese in 2013 and A Translation Course of Science and Technology in 2014. 